\title{
DURATION DEPENDENT ANTIAPOPTOTIC EFFICACY OF CAMELLIA SINENSIS (GREEN TEA) ON STREPTOZOTOCIN INDUCED DIABETES LINKED TESTICULAR HYPOFUNCTION IN ALBINO RAT: GENOMIC AND FLOW CYTOMETRIC ASSESSMENT
}

\author{
BARNALI DAS, BAISAKHI BISWAS, DEBIDAS GHOSH ${ }^{*}$
}

Molecular Medicine and Nutrigenomics Research Laboratory, Department of Bio-Medical Laboratory Science and Management, Vidyasagar University, Midnapore, West Bengal, India 721102

Email: debidas_ghosh@yahoo.co.in

Received: 04 Dec 2018 Revised and Accepted: 02 May 2019

\section{ABSTRACT}

Objective: The study has been conducted to search out the threshold duration of treatment of ethyl acetate fraction of methanolic extract of leaves of Camellia sinensis (L.) Kuntze at the dose of $100 \mathrm{mg} / \mathrm{kg}$ body weight for the management of diabetes-induced testicular impairment in streptozotocin-induced diabetic rat in a duration dependent fashion.

Methods: In this respect, the glycemic, androgenic, oxidative stress sensors, gene expression of testicular androgenic key enzymes along with apoptotic markers were evaluated in a duration dependent way (14, 28 and $56 \mathrm{~d}$ ).

Results: A significant correction was noted in the levels of glycated haemoglobin (HbA1c), testicular thiobarbituric acid reactive substances (TBARS), conjugated diene (CD), sperm viability, sperm mitochondrial status, serum testosterone, and genomic expression of testicular $\Delta 5$, $3 \beta$ hydroxysteroid dehydrogenase (HSD), $17 \beta$-HSD, Bax, Bcl-2 after treatment for different duration with the said fraction in diabetic groups in compare to respective vehicle-treated diabetic group without any toxicity induction in general. Thin layer chromatography (TLC) study of the fraction showed two spots with retention factors (Rf) of 0.78 and 0.51 .

Conclusion: The results showed that $28 \mathrm{~d}$ treatment was threshold duration of treatment for the correction of diabetes-induced testicular impairment.

Keywords: Camellia sinensis, Diabetes, Oxidative stress, Flow cytometry, Testicular dysfunction, Apoptosis

(C) 2019 The Authors. Published by Innovare Academic Sciences Pvt Ltd. This is an open-access article under the CC BY license (http://creativecommons.org/licenses/by/4.0/) DOI: http://dx.doi.org/10.22159/ijpps.2019v11i6.31150

\section{INTRODUCTION}

Diabetes mellitus is a metabolic disorder resulting from a defect in insulin secretion, insulin action, or both [1]. The pathology of diabetes mellitus is caused by Reactive Oxygen Species (ROS) that activate the non-enzymatic glycation of proteins which leads to structural and functional changes in proteins, DNA and lipid. The chronic diabetes is associated with the damage and dysfunction of various organs including testes [2] and hampered different vital functions of the reproductive system in model animal and human either directly or indirectly [3]. Many studies have been focused that streptozotocin (STZ) induced diabetes in male rat resulted diminution in the activity of sex organs, low sperm count along with a low level of testosterone $[4,5]$. Spermatogenic cells at different stages of spermatogenesis are prone to routine apoptosis, and elevation in the level of apoptosis may cause male infertility [6]. The number of people with diabetes is increasing due to urbanization, altered food style, increasing prevalence of obesity, and physical inactivity [7]. Plant-derived preparations have been used as traditional remedies and in folklore medicine for the treatment of diabetes in many parts of the world [8, 9]. Traditional medicinal herbs are well accepted by the World Health Organization (WHO) expert committee to treat the diabetes mellitus due to its minimum side effect, low cost and easy availability [10,11].

Camellia sinensis (Theaceae) leaves named as tea which is used in the form beverage and at present, it is claimed as a second popular beverage after water. In recent years $C$. sinensis is widely used to study its beneficial effects for the treatment and prevention of cancer, cardiovascular disease and diabetic complications [12-14]. Studies showed that administration of green tea (C. sinensis) to STZ induced diabetic rats promoted blood glucose reduction and antioxidant effects $[15,16]$. Evidence provided through literature that green tea is useful for the management of diabetes mellitus, but no studies to date have tested the efficacy of green tea to prevent testicular dysfunctions associated with diabetes mellitus.
From our previous study, an ethyl-acetate fraction of methanolic extract of green tea at the dose of $100 \mathrm{mg} / \mathrm{kg}$ body weight has been selected as potent dose and as potent solvent fraction for the management of diabetes-induced testicular hypofunction. Therefore, in this experiment; an approach has been considered to find out the threshold duration of treatment in this concern.

\section{MATERIALS AND METHODS}

Chemicals

The chemicals and solvents were purchased from Sigma-Aldrich Chemicals Private Limited, Bangalore or from Merck (KGaA, Germany) or from Crest Biosystems, Goa, India or from standard manufacturers.

\section{Preparation of fraction from methanolic extract}

The leaves of $C$. sinensis (green tea) were used in this study. The green tea was purchased from Subodh Brothers Pvt. Ltd. (Kolkata) and preserved in an airtight manner. Preparation of crude extract of leaves of C. sinensis using-methanol and its fractionation using different solvents as per polarity grades such as n-hexane, ethyl acetate and chloroform were performed according to our laboratory standard method [17] These lyophilized fractions were collected, labeled and stored at $4{ }^{\circ} \mathrm{C}$ until use. Out of these, the ethyl acetate fraction was used for this study as a potent fraction as per our previous study [13].

Selection criteria of animal and animal care

Rats were procured from an authorized vendor and housed in a well-ventilated animal house. Standard environmental conditions, i.e. $22-25{ }^{\circ} \mathrm{C}$ temperature, $45 \%$ relative humidity and $12 \mathrm{hr}$.: $12 \mathrm{hr}$. light-dark cycles were maintained. Before conduction the experiment, animals were kept in the animal house for $7 \mathrm{~d}$ to acclimatize the laboratory conditions. The animals were provided standard rat chow (supplied by Golden Feeds, Mehrauli, New Delhi) 
and water ad libitum. Adult 58 male rats of Wistar strain (80-90 d old) having body weight $140 \pm 10 \mathrm{~g}$ were used in this study. Forty rats made diabetic and out of these thirty-six rats fulfill the moderate diabetic criteria (fasting blood glucose level $>250 \mathrm{mg} / \mathrm{dl}$ but $<350$ $\mathrm{mg} / \mathrm{dl}$ ) [18]. The rest animals were not considered due to the lack of a stable diabetic state. Eighteen normoglycemic healthy rats were served as a control in three respective duration dependent treatment schedule designed below. The Institutional Ethics Committee (IEC) of Vidyasagar University gave the approval prior to conduct the experiment (IEC Approval No-IEC/3/C-5/14; Dated$3 / 11 / 14$ ). The guidelines are given by the CPCSEA (Committee for the Purpose of Control and Supervision of Experiments on Animals), Govt. of India, were strictly maintained.

\section{Induction of diabetes mellitus}

Rats were kept for $24 \mathrm{~h}$ fasting conditions and then single intramuscular injection of STZ ( $40 \mathrm{mg} / \mathrm{kg}$ body weight) was given to the rats that produce moderate diabetes. Subsequent six days were allowed for the stability of diabetes and after that, the rats were selected for the experiment subject to fulfillment of the said criteria.

\section{Experimental protocol}

Before starting the treatment, all the rats were divided into 9 groups of 6 animals each. Except for control group, other 6 groups were made diabetic by STZ injection.

Animals were categorized as follows-

Group I (Vehicle treated control for $14 \mathrm{~d}$ ): Rats of this group were normoglycemic i.e. having fasting blood glucose level $70-99 \mathrm{mg} / \mathrm{dl}$ and subjected to oral feeding of distilled water at the dose of $2 \mathrm{ml} / \mathrm{kg}$ body weight ( 2 times/rat/day) as vehicle treatment for $14 \mathrm{~d}$.

Group II (Vehicle treated diabetic for $14 \mathrm{~d}$ ): Streptozotocin-induced diabetic rats of this group were also treated with $2 \mathrm{ml}$ distilled water/kg body weight ( 2 times/rat/day) as for $14 \mathrm{~d}$.

Group III (Diabetic + C. sinensis treated group for $14 \mathrm{~d}$ ): Ethyl-acetate fraction prepared from methanolic extract of $C$. sinensis (green tea) used for the treatment of the diabetic rat in this group at the dose of $100 \mathrm{mg} / \mathrm{kg}$ body weight in $2 \mathrm{ml}$ of distilled water twice/day for $14 \mathrm{~d}$.

Group IV (Vehicle treated control for $28 \mathrm{~d}$ ): Rats of this group were normoglycemic and subjected to oral feeding of distilled water at the dose of $2 \mathrm{ml} / \mathrm{kg}$ body weight ( 2 times/rat/day) as vehicle treatment for $28 \mathrm{~d}$.

Group V (Vehicle treated diabetic for 28 d): Streptozotocin-induced diabetic rats of this group were also treated with $2 \mathrm{ml}$ distilled water/kg body weight ( 2 times/rat/day) as vehicle treatment for $28 \mathrm{~d}$.

Group VI (Diabetic+C. sinensis treated group for $28 \mathrm{~d}$ ): Ethyl-acetate fraction prepared from methanolic extract of $C$. sinensis (green tea) used for the treatment of the diabetic rat in this group at the dose of $100 \mathrm{mg} / \mathrm{kg}$ body weight in $2 \mathrm{ml}$ of distilled water twice/day for $28 \mathrm{~d}$.

Group VII (Vehicle treated control group for $56 \mathrm{~d}$ ): Rats of this group were normoglycemic subjected to oral feeding of distilled water at the dose of $2 \mathrm{ml} / \mathrm{kg}$ body weight (2 times/rat/day) as vehicle treatment for $56 \mathrm{~d}$.

Group VIII (Vehicle treated diabetic group for $56 \mathrm{~d}$ ): Streptozotocininduced diabetic rats of this group were also treated with $2 \mathrm{ml}$ distilled water/kg body weight (2 times/rat/day) as vehicle treatment for $56 \mathrm{~d}$.

Group IX (Diabetic + C. sinensis treated group for $56 \mathrm{~d}$ ): Ethyl-acetate fraction prepared from methanolic extract of $C$. sinensis (green tea) used for the treatment of the diabetic rat in this group at the dose of $100 \mathrm{mg} / \mathrm{kg}$ body weight in $2 \mathrm{ml}$ of distilled water twice/day for $56 \mathrm{~d}$.

The first oral dose of distilled water (in case of control and diabetic group) or fraction (in case of treated diabetic group) of this said treatment regimen was given in fasting condition (at 10:00 a. m.) and for this purpose the food container from each cage was removed at 8.00 a. m. Animal feed was supplied $2 \mathrm{hr}$ later after extract/vehicle treatment. A second oral dose of the same was administered in the afternoon (at 4:00 pm) and condition for feed supply was followed as before to minimize the drug-nutrient interaction if any.

All the rats were sacrificed at fasting state using euthanasia box on $29^{\text {th }}$ day of treatment. From the hepatic vein, blood was collected. Liver and testis were dissected out and stored at-20 ${ }^{\circ} \mathrm{C}$ for the biochemical and genomic analysis.

\section{Measurement of glycaemic bio-sensor}

Glycated hemoglobin level (HbA1c) was measured using a glucose memory test according to the standard method [19]. Glycated hemoglobin level was expressed as $\mathrm{GHb} \%$.

\section{Estimation of the oxidative stress biomarker}

For the quantification of thiobarbituric acid reactive substances (TBARS) and a conjugated diene (CD) the testicular tissue was homogenized and centrifuged at $10000 \times \mathrm{g}$ at $4{ }^{\circ} \mathrm{C}$ for $5 \mathrm{~min}$. The supernatant was transferred in spectrophotometer cuvette and absorbances were noted at $535 \mathrm{~nm}$ for the quantification of TBARS [20], and at $233 \mathrm{~nm}$ to measure CD [21].

\section{Measurement of reproductive profile}

For the counting of live and dead sperm cells through Accuri C6 flow cytometer, BD Cell Viability Kit Cat No 349480 was used. Epididymal fluids were collected and mix with $1.8 \mathrm{ml}$ of pre-warmed Tris buffer $\left(1 \times 10^{6} \mathrm{cell} / \mathrm{ml}\right.$ of cell suspension). Then, $2 \mu \mathrm{l}$ of Thiazole Orange (TO) and $2 \mu \mathrm{l}$ of Propidium Iodide (PI) were added and incubated at $37{ }^{\circ} \mathrm{C}$ for $5 \mathrm{~min}$ [22]. The data were acquired on flow cytometer according to the Standard Operating Procedure (SOP) of this kit.

Mitochondrial status of spermatozoa was assessed by Accuri C6 flow cytometer using JC1 kit from BD Cat No 551302 and dimethyl sulfoxide solution. Fifty microliters of epididymal fluid and five microliters of JC1 staining solution were taken and then incubated in dark at $37{ }^{\circ} \mathrm{C}$ for $10 \mathrm{~min}$. Five $\mathrm{ml}$ assay buffer was added and centrifuged at $1200 \mathrm{rpm}$ for $5 \mathrm{~min}$, then the supernatant was discarded. Cells in $500 \mu \mathrm{l}$ were resuspended in assay buffer and data was acquired on flow cytometer according to supplied Standard Operating Procedure (SOP) of this kit [23].

By solid phase-conjugated assay, the level of serum testosterone was measured. The kit was purchased from Lilac Medicare (P) Ltd, Mumbai, India. The optical density was measured using the standard method [24]. The intra-assay variation was $5.2 \%$. No inter-assay variation was considered here as all the samples were measured at a time. The cross-reaction level with androstenedione was $0.09 \%$ and dihydrotestosterone was $1.7 \%$.

Gene expression of pro-apoptotic, anti-apoptotic biomarkers and androgenic key enzymes

The primers of Bax, Bcl-2, Glyceraldehyde 3-phosphate dehydrogenase (GAPDH), $\Delta^{5}, 3 \beta-\mathrm{HSD}, 17 \beta-\mathrm{HSD}$ and Transferrin Receptor (TFR) were procured from Sigma-Aldrich Chemicals Private Limited, Bangalore. Light Cycler 480 II (Roche Diagnostic) was used for the assessment of expression of the above genes of testicular tissues [25]. For RNA extraction, Roche Diagnostic's kit was used. Residual DNA was removed and cDNA was synthesized using a kit ("Transcriptor First Strand Synthesis Kit" Roche Diagnostics, Mannheim, Germany Product No. 04897030 001).

\section{Assessment of metabolic toxicity}

For the measurement of hepatic GOT and GPT activities, kits were used supplied by Creast Bio-systems, Gitanjali, Dr. Antonio Do RegoBagh, Alto Santacruz, Bambolim Complex (Goa, India) and the standard protocol was followed [26].

\section{Statistical analysis}

All data were expressed as mean \pm Standard Error of Mean (SEM), $(n=6)$. For the statistical analysis of data, 'Analysis of Variance (ANOVA) followed by multiple comparison student's two tail t-test' was performed [27]. Differences were considered significant at 0.05 . 


\section{Thin layer chromatography (TLC) of the fraction}

Thin layer chromatographic study of an ethyl acetate fraction of $C$. sinensis was conducted by using commercially available aluminium sheets of Silica gel 60 F254 (Merck) with dichloromethane (DCM): Methanol: : 80: 20 as the solvent system. After the test, the plates were dried under a stream of hot air and then examined within a UV cabinet at short wavelength $(254 \mathrm{~nm}$ ) and long wavelength (366 $\mathrm{nm}), \mathrm{H}_{2} \mathrm{SO}_{4}$ charing and $\mathrm{I}_{2}$ maturation [28].

\section{RESULTS}

\section{Effect on glycaemic bio-sensor}

Glycated hemoglobin (HbA1c) level was significantly elevated $(\mathrm{p}<0.05)$ in all the vehicle-treated diabetic groups i.e. 14,28 or $56 \mathrm{~d}$ experimental schedule in respect to the corresponding vehicletreated control groups. Administration of ethyl acetate fraction of methanolic extract of $C$. sinensis at the dose of $100 \mathrm{mg} / \mathrm{kg}$ body weight in $2 \mathrm{ml}$ of distilled water two times/day for the duration of 14 or 28 or $56 \mathrm{~d}$ to diabetic rats, a significant diminution $(\mathrm{p}<0.05)$ in the level of this parameter was observed in respect to vehicletreated diabetic group of respective experimental schedule. Treatment of ethyl acetate fraction for the duration of 28 or $56 \mathrm{~d}$ to the diabetic rats resulted in more significant recovery $(p<0.05)$ in the level of glycated hemoglobin in respect to $14 \mathrm{~d}$ fraction treated diabetic animal towards the control. No significant difference was found in the value of the above parameter when the results were compared between the 28 or $56 \mathrm{~d}$ of ethyl acetate fraction treated diabetic groups which indicated that $28 \mathrm{~d}$ is the threshold duration of treatment in this concern (fig. 1).

\section{Assessment of oxidative stress biomarkers}

A significant elevation $(\mathrm{p}<0.05)$ was observed in the levels of $C D$ and TBARS in the testicular tissues in all the duration dependent diabetic groups when the comparison was made to their respective control group for the said treatment schedules. There was significant $(p<0.05)$ corrections in the quantity of said parameters towards their control levels after treatment with ethyl acetate fraction for 14 or 28 or $56 \mathrm{~d}$ duration. Out of these, ethyl acetate fraction treatment for a period of 28 or $56 \mathrm{~d}$ produced rectifications that significantly $(p<0.05)$ higher with rectification achieved after $14 \mathrm{~d}$ of fraction treatment. The levels of these parameters were found with insignificant $(p>0.05)$ difference from each other for the treatment period between 28 or $56 \mathrm{~d}$ (fig. $2 \mathrm{~A}, \mathrm{~B}$ ).

\section{Assessment of reproductive profile}

In all the duration dependent vehicle-treated diabetic groups, sperm viability was decreased significantly $(\mathrm{p}<0.05)$ in respect to the vehicle-treated control group of corresponding experimental schedule. After the treatment of ethyl acetate fraction of methanolic extract of $C$. sinensis for 14 or 28 or $56 \mathrm{~d}$ to the diabetic animals, sperm viability was increased significantly $(p<0.05)$ in compare with the corresponding vehicle treated STZ induced diabetic animals. Results also showed that administration of said fraction for the duration of 28 or $56 \mathrm{~d}$ resulted in a significant elevation $(\mathrm{p}<0.05)$ of sperm viability in compare to $14 \mathrm{~d}$ fraction treatment. No significant variation was noted in the case of sperm viability between 28 or 56 $\mathrm{d}$ fraction treated diabetic groups (fig. $3 \mathrm{~A}, \mathrm{~B}$ ).

Depolarised sperm indicated the low mitochondrial status of sperm. Percentage of sperm with the depolarised mitochondrial membrane was increased significantly $(\mathrm{p}<0.05)$ in all the duration dependent vehicle-treated diabetic groups in respect to the vehicle-treated control group of corresponding experimental schedule. Numbers of depolarised sperm were decreased significantly $(\mathrm{p}<0.05)$ in diabetic animals treated with above-said fraction for 14 or 28 or $56 \mathrm{~d}$ in compare with the corresponding vehicle-treated diabetic animals. It was also observed that 28 or $56 \mathrm{~d}$ fraction treated groups showed significant promising effect $(\mathrm{p}<0.05)$ than $14 \mathrm{~d}$ treated diabetic group. No significant variation in the level of this parameter was observed between 28 or $56 \mathrm{~d}$ fraction treated diabetic groups (fig. $4 \mathrm{~A}, \mathrm{~B}$ ).

Level of serum testosterone was significantly decreased $(p<0.05)$ in all the duration dependent diabetic groups in respect to the vehicletreated control group. Treatment with above-said fraction for the duration of 14 or 28 or $56 \mathrm{~d}$ to diabetic rats resulted in a significant recovery $(\mathrm{p}<0.05)$ in the level of serum testosterone in respect to diabetic group. Results focused that 28 or $56 \mathrm{~d}$ of fraction treatment resulted in a significant correction $(\mathrm{p}<0.05)$ in compare with $14 \mathrm{~d}$ of fraction treated diabetic groups. There was no significant variation in the levels of this parameter between 28 or $56 \mathrm{~d}$ fraction treated diabetic groups (fig. 5).

\section{Gene expression pattern of testicular apoptotic marker}

Upward and downward expression patterns were noted in case of the pro-apoptotic gene, i.e. Bax and anti-apoptotic gene, i.e. Bcl-2 in testicular tissue respectively through qRT-PCR analysis in the diabetic group when compared to the vehicle-treated control group. A significant $(\mathrm{p}<0.05)$ recovery was observed towards the control group in the expression levels of Bax and Bcl-2 genes after treatment with above-mentioned fraction for the duration of 14 or 28 or $56 \mathrm{~d}$ in diabetic rat. When the results of 28 or $56 \mathrm{~d}$ fraction treated groups compared with $14 \mathrm{~d}$ fraction treated group, it was observed that 28 or $56 \mathrm{~d}$ duration significantly effective $(\mathrm{p}<0.05)$ in this concern in compare with $14 \mathrm{~d}$ duration of treatment. No significant difference was noted between 28 or $56 \mathrm{~d}$ of fraction treatment to diabetic animals (fig. $6 \mathrm{~A}, \mathrm{~B}$ ).

\section{Gene expression of androgenic key enzymes}

Levels of expression of testicular $\Delta 5,3 \beta$-HSD and $17 \beta$-HSD genes were decreased insignificant level $(\mathrm{p}<0.05)$ in the diabetic group in respect to the control group. After treatment with above-said fraction for the duration of 14 or 28 or $56 \mathrm{~d}$ to diabetic rats resulted in a significant recovery $(\mathrm{p}<0.05)$ in the transcript levels of concerned genes in respect to diabetic group. Results focused that 28 or $56 \mathrm{~d}$ of fraction treatment resulted in a significant correction $(\mathrm{p}<0.05)$ in compare with $14 \mathrm{~d}$ of fraction treated diabetic group. There was no significant variation in the levels of this parameter between 28 or $56 \mathrm{~d}$ fraction treated diabetic groups (fig. $7 \mathrm{~A}, \mathrm{~B}$ ).

\section{Glycated hemoglobin (HbA1c)}

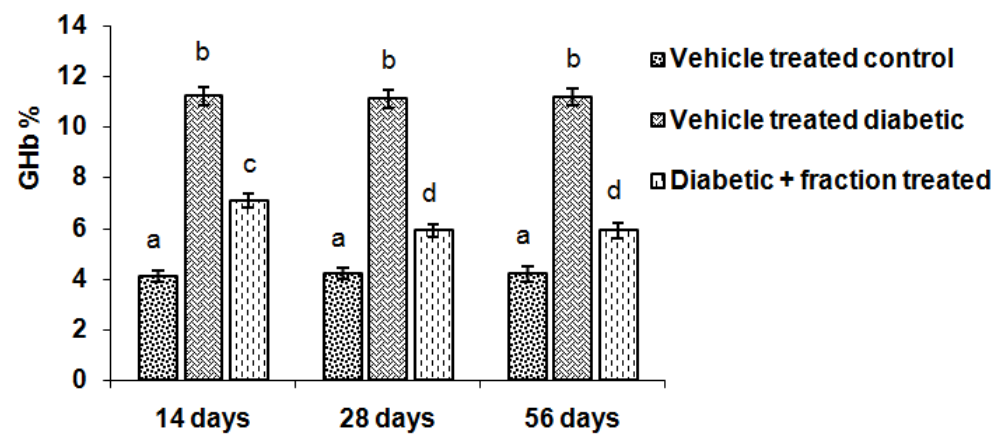

Fig. 1: Protective effect of ethyl-acetate fraction of $C$. sinensis on glycated hemoglobin level $\left(\mathrm{HbA}_{1} \mathrm{c}\right)$ in STZ-induced diabetic male albino rat. Data represents mean \pm SEM $(n=6)$. ANOVA followed by multiple comparison student's two tail-t-test. Bars with different superscript (a, b, c, d) differ from each other significantly, $p<0.05$ 


\section{Toxicity studies}

Activities of hepatic GOT, GPT were increased in all duration dependent diabetic groups when the comparison was made with the vehicle-treated control group. Above said fraction treatment for the duration of 14 or 28 or $56 \mathrm{~d}$ to diabetic rats can able to recover the enzyme activities towards the control at a significant level $(p<0.05)$ (fig. $8 \mathrm{~A}, \mathrm{~B}$ ).

\section{Thin layer chromatographic study}

Two spots were found from the analytical study of thin layer chromatogram of an ethyl acetate fraction of $C$. sinensis (fig. 9) after examined in UV cabinet at short wavelength $254 \mathrm{~nm}$ and long wavelength $366 \mathrm{~nm}, \mathrm{H}_{2} \mathrm{SO}_{4}$ charing and Iodine maturation. Retention factor (Rf) of these compounds were 0.78 and 0.51 and the running distance of solvent was $7 \mathrm{~cm}$ (fig. 9).

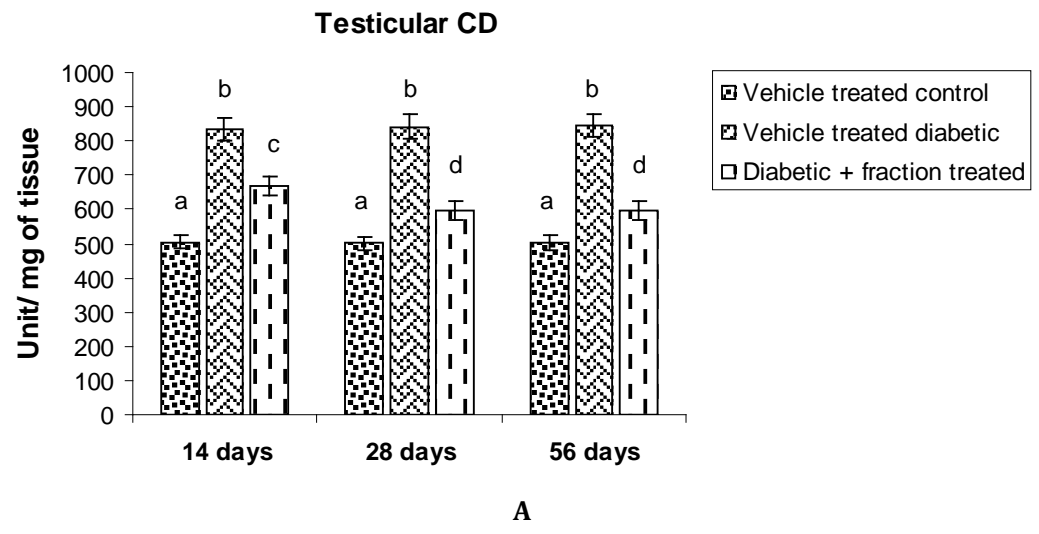

Testicular TBARS

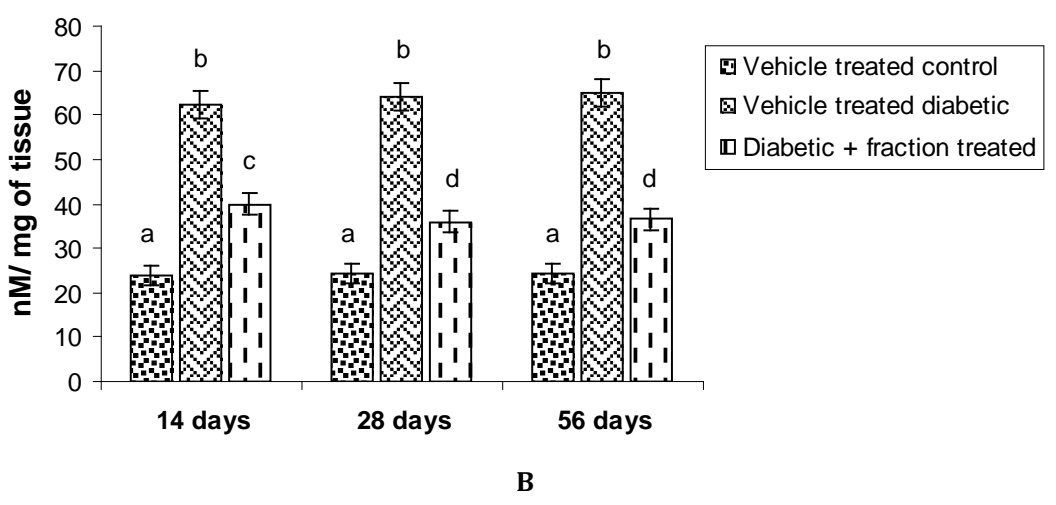

Fig. 2: Duration dependent effect of ethyl-acetate fraction of $C$. sinensis on the levels of (A) Conjugated diene (CD) and (B) TBARS in testicular tissue of an experimental animal. Bars indicate mean \pm SEM $(n=6)$. ANOVA followed by multiple comparison student's two tail-ttest. Bars with different superscripts (a, b, c, d) differ from each other significantly, p<0.05

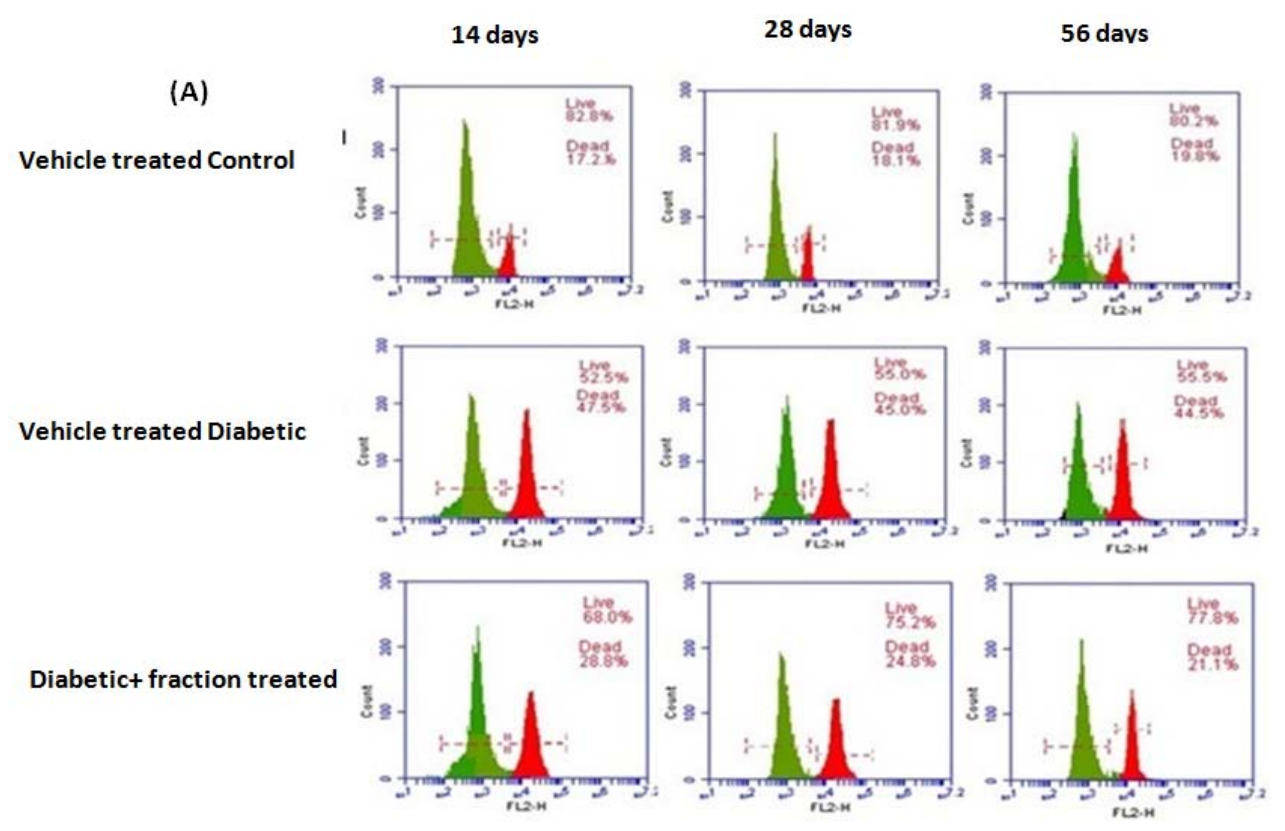




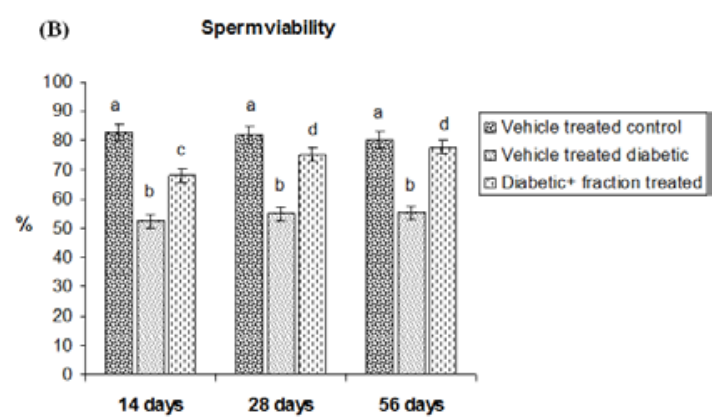

Fig. 3: Corrective effect of ethyl acetate fraction of $C$. sinensis on epididymal sperm viability. (A) Histogram of sperm viability stained with propidium iodide (PI) by flow cytometric analysis. (B) Bar diagram of viable sperms in fraction treated group. Bars indicate mean \pm SEM (n = 6). ANOVA followed by multiple comparison student's two-tail t-test. Bars with different superscripts (a, b, c, d) differ from each other significantly, $\mathbf{p}<0.05$

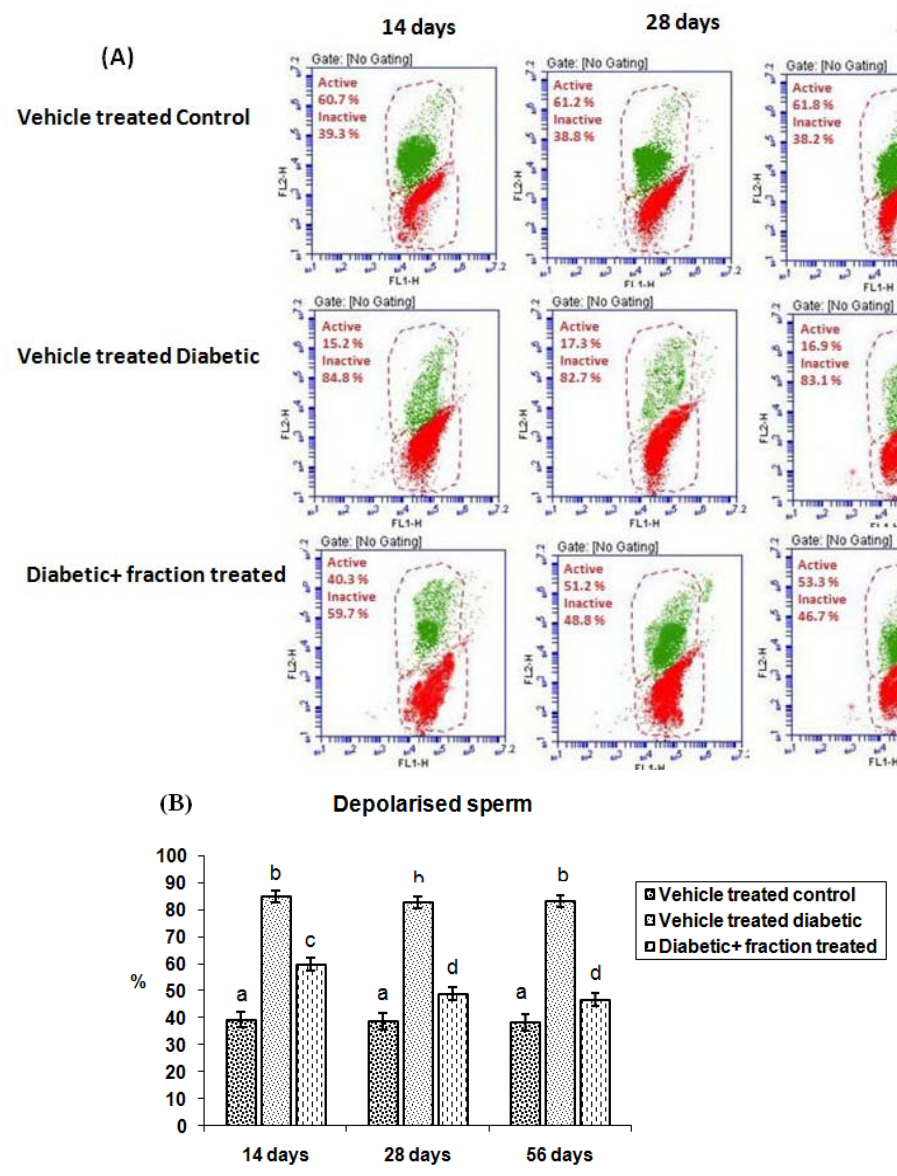

Fig. 4: Protective effect of ethyl acetate fraction of $C$. sinensis on sperm mitochondria. (A) Histogram of depolarised sperm after JC-1 staining. Units indicate fluorescence intensity (FL1 and FL2 stand for green and orange fluorescence, respectively). (B) Bar diagram of depolarised sperm. Bars indicate mean $\pm \operatorname{SEM}(n=6)$. ANOVA followed by multiple comparison student's two-tail t-test. Bars with different superscripts (a, b, c, d) differ from each other significantly, $p<0.05$

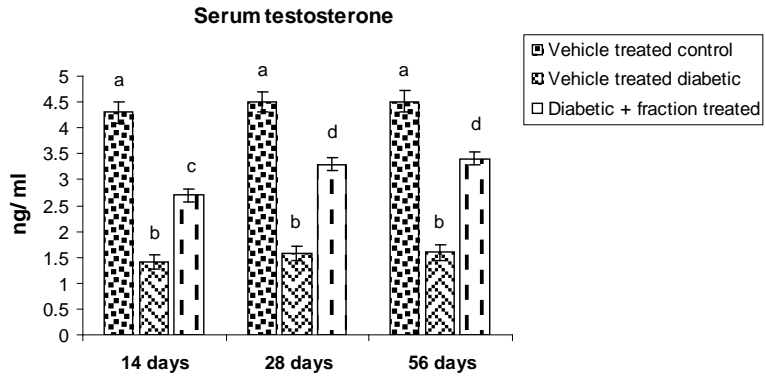

Fig. 5: Recovery in serum testosterone level after administration of ethyl acetate fraction of methanolic extract of $C$. sinensis in streptozotocin $(S T Z)$-induced diabetic rat. Bars represent mean \pm SEM $(n=6)$. ANOVA followed by multiple comparison student's two tailt-test. Bars with different superscripts (a, b, c, d) differ from each other significantly, $p<0.05$ 

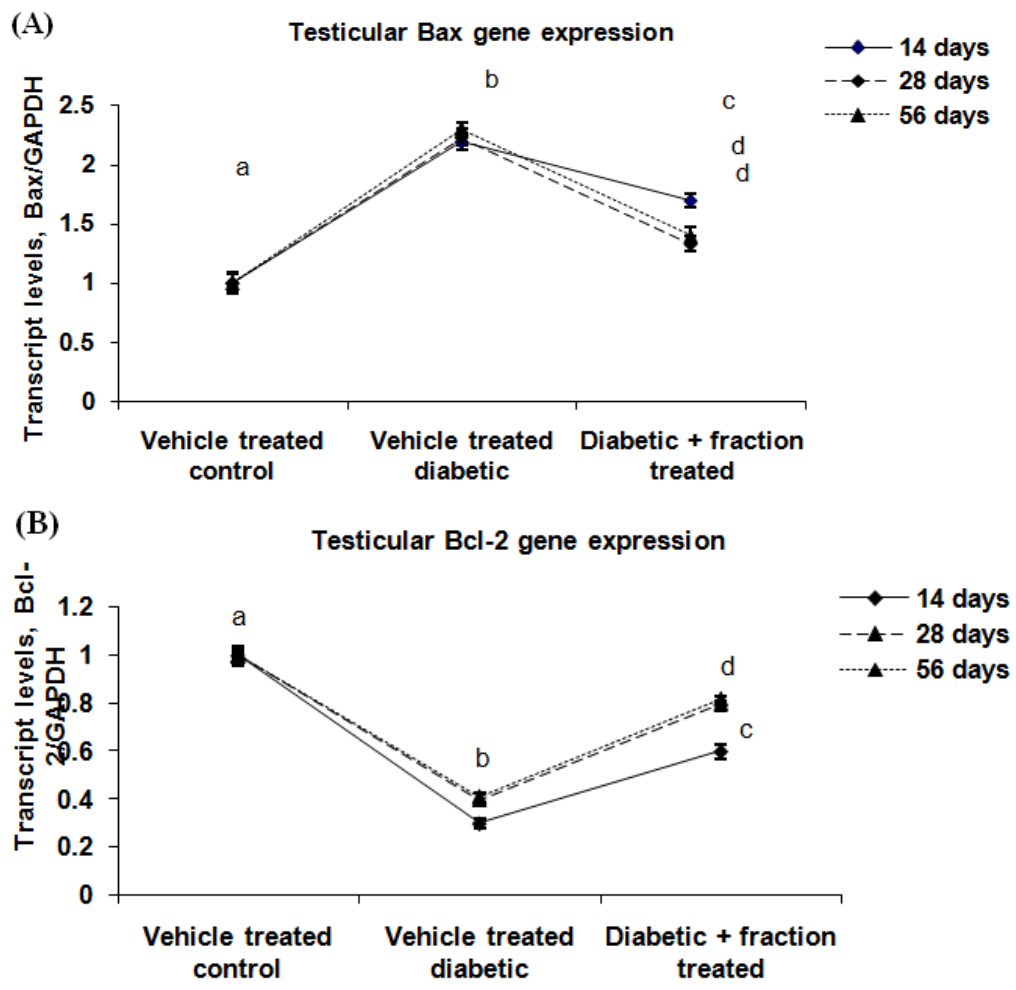

Fig. 6: Expression pattern of testicular (A) Bax gene and (B) Bcl-2 gene by qRT-PCR analysis in rat. Data represents mean \pm SEM ( $n=6$ ). ANOVA followed by multiple comparison student's two tail't' test. Points on the line with different superscripts (a, b, c, d) differ from each other significantly, $\mathbf{p}<0.05$

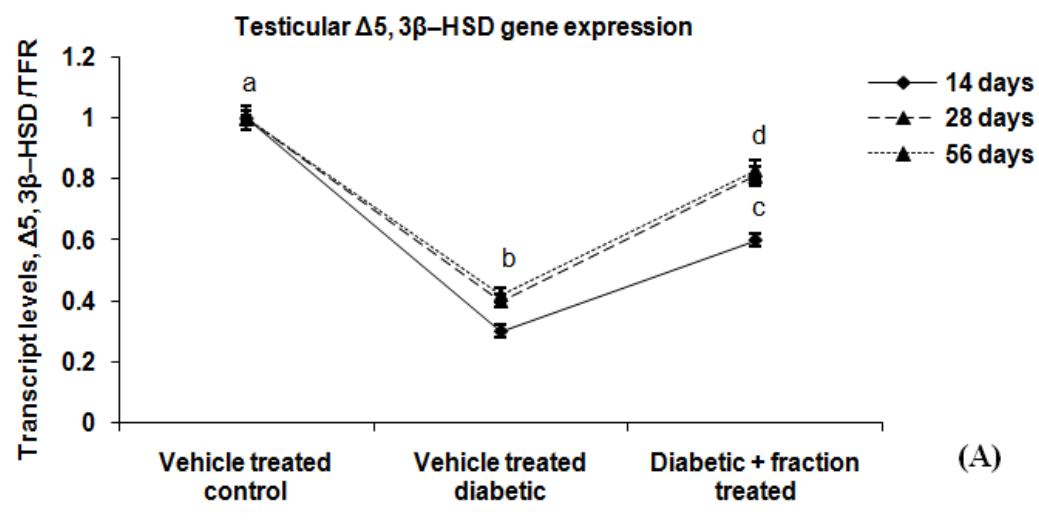

Testicular $17 \beta-H S D$ gene expression

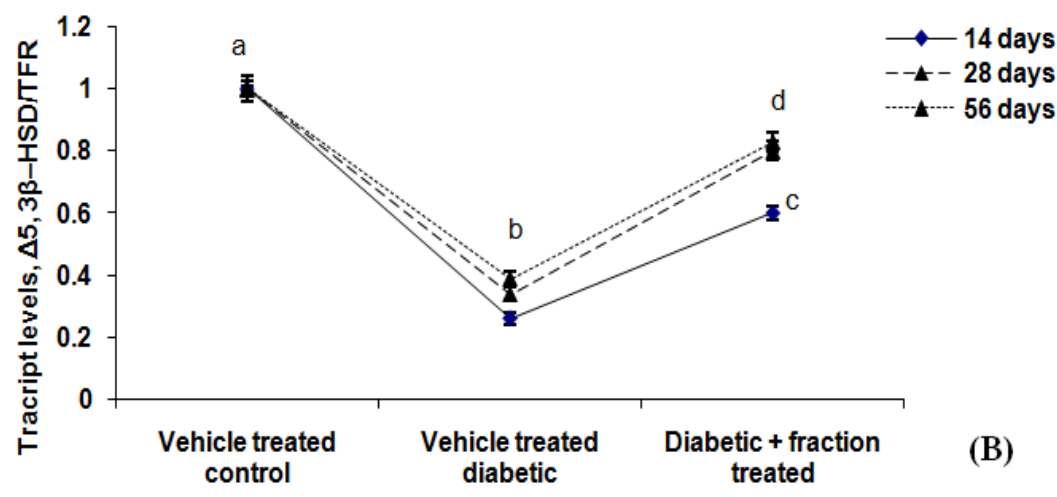

Fig. 7: Expression pattern of testicular (A) $\Delta 5-3 \beta-H S D$ gene and (B) 17 $\beta$-HSD gene by qRT-PCR analysis in rat. Data represents mean \pm SEM $(n=6)$. ANOVA followed by multiple comparison student's two tail' $t$ ' test. Points on the line with different superscripts $(a, b, c, d)$ differ from each other significantly, $p<0.05$ 
Hepatic GOT

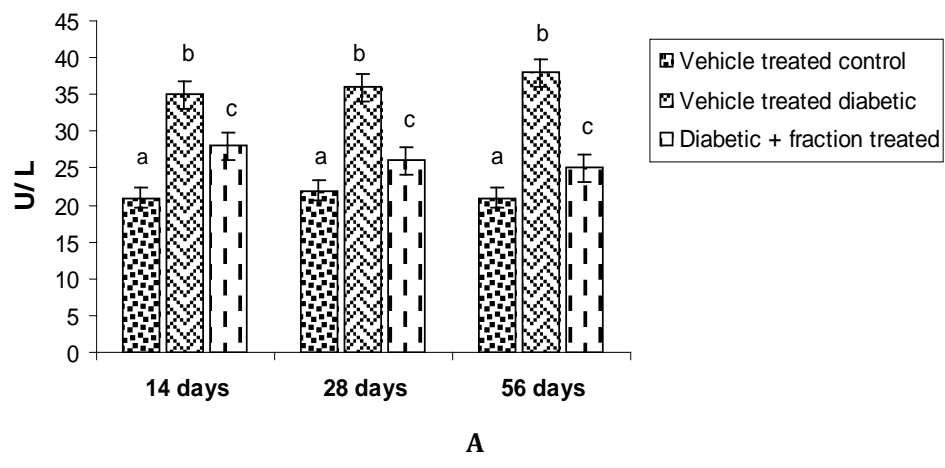

Hepatic GPT

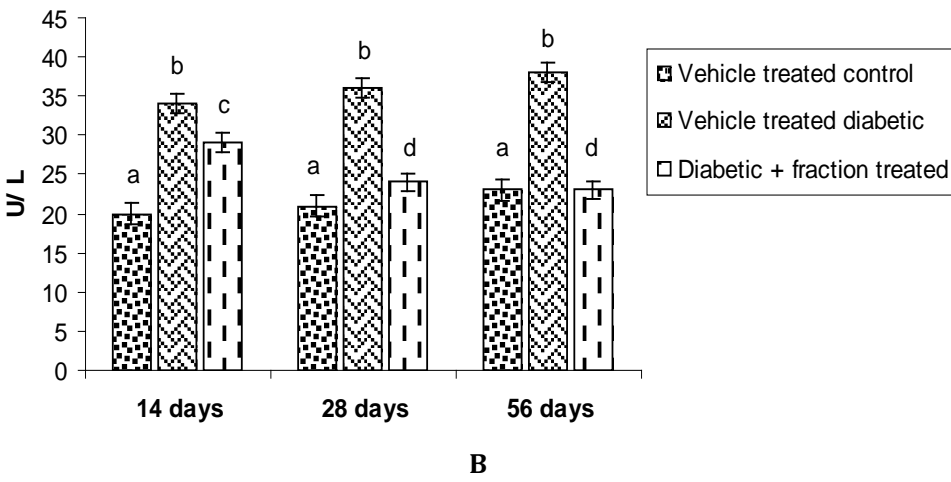

Fig. 8: A and B indicate a recovery in hepatic GOT and GPT activities after treatment with an ethyl-acetate fraction of $C$. sinensis leaves in $S T Z$-induced diabetic male albino rat. Data represents mean \pm SEM $(n=6)$. ANOVA followed by multiple comparison student's two tail't 'test. Bars with different superscripts (a, b, c, d) differ from each other significantly, $p<0.05$

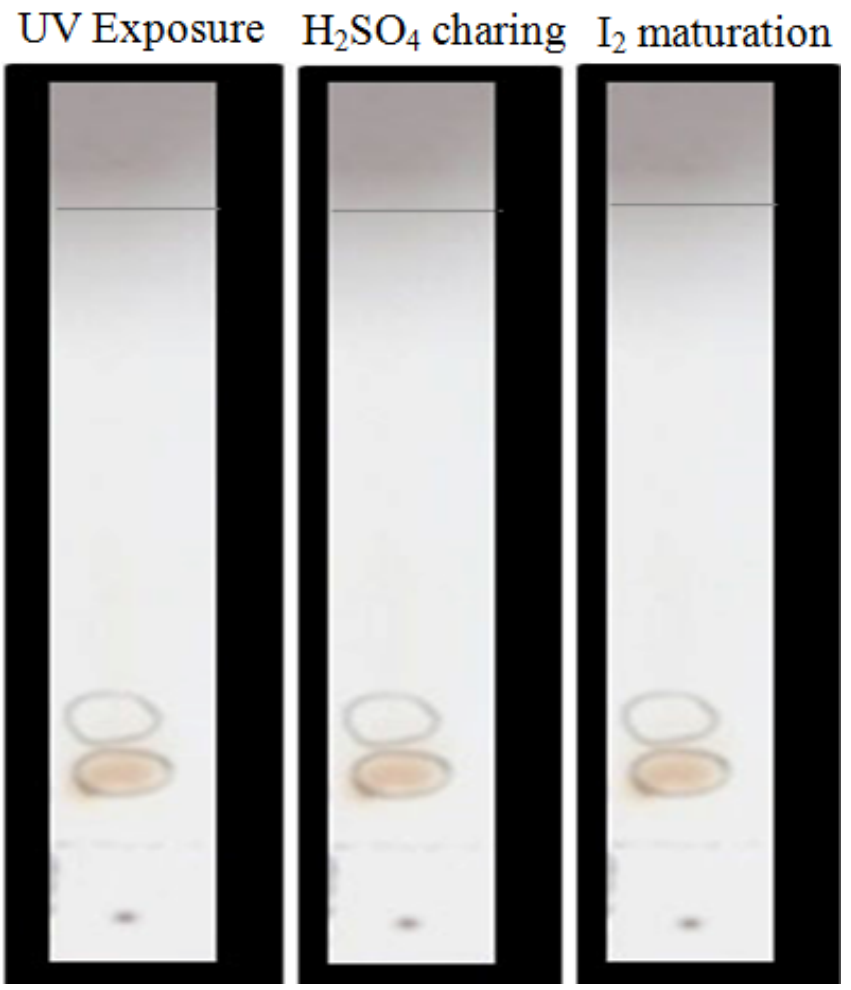

Fig. 9: TLC plates of an ethyl-acetate fraction of methanolic extract of $C$. sinensis, two spots were found in all the above cases 


\section{DISCUSSION}

Diabetes is associated with reproductive hypofunction related problems including erectile dysfunction, low semen quality and loss of libido $[29,30]$. The present experiment has been conducted for the correction of testicular impairment in streptozotocin-induced diabetic rat to find out the threshold duration of the treatment with an ethyl-acetate fraction of methanolic extract of $C$. sinensis at the dose of $100 \mathrm{mg} / \mathrm{kg}$ body weight to minimize the bioburden of phytomolecules on biological systems. The ethyl-acetate fraction at the dose of $100 \mathrm{mg} / \mathrm{kg}$ body weight has been selected as a most potent fraction out of other doses used here as the said dose showed more promising results without imposing any metabolic toxicity [13]. Elevation in the glycated hemoglobin level in all three duration dependent diabetic groups confirms the diabetic condition [31]. Flow cytometric analysis of sperm showed that the percentage of dead sperm cells and sperms with depolarised mitochondrial membrane were increased in the diabetic group that confirmed the testicular impairment in diabetic condition. Depolarised sperm indicates low mitochondrial status of sperm [32, 33]. Decreased serum testosterone level in the diabetic group confirmed the testicular hypofunction as testosterone is prime hormone for regulating testicular activities including spermatogonia [34]. Treatment with the ethyl acetate fraction for above said three duration to diabetic rats resulted in a significant recovery in the above parameters, may be due to increase in the activities of testicular androgenic key enzymes, i.e. $\Delta^{5}, 3 \beta-$ HSD and $17 \beta$-HSD [34]. One possible mechanism may be the effect of the phytomolecules (s) present in the fraction to switch on the androgenic enzymatic genes, noted here from qRT-PCR study. Another view about diabetes linked testicular hypofunction may be oxidative stress-mediated disorder [35]. Oxidative stress imposition in testicular tissue of diabetic animals was developed at different duration which has been assessed here from the significant elevation in the levels of the end products of free radical i.e. CD and TBARS in testis which may be due to high level of uncoupler protein synthesis in reproductive organs [36] which leads to increased reactive oxygen species (ROS) generation. After treatment of the different duration of ethyl acetate fraction, a significant recovery was observed in this concern. This result enlighted that this recovery by this phyto-ingredients present in ethyl acetate fraction may correct this ROS by controlling diabetes and testosterone synthesis as hyperglycaemia as well as low testosterone are associated with ROS generation [37].

To find out the apoptotic status of testicular germ cells in such conditions, the expression pattern of pro-apoptotic marker like Bax and anti-apoptotic marker like Bcl-2 genes were studied [38]. The testicular Bax gene-focused the upward nature and Bcl-2 gene showed a downward nature of expression in all duration dependent diabetic groups. Ethyl acetate fraction treatment can able to recover the expression patterns of above biomarkers in all the duration of the treatment by nutraceutical mediated switch on of gene expression which pointed out the presence of anti-apoptotic nature of the phytochemicals in the said fraction. Out of above said three duration of treatment it is established that $28 \mathrm{~d}$ is the threshold duration of treatment and if the duration of treatment is lengthen, there is no further correction of the concerned parameter. So, considering all the results it may be hypothesised that the active phytomolecule(s) present in the said fraction correct the male germ cell apoptosis by decreasing Bax gene expression which results diminution in mitochondrial depolarization of sperm cell and therefore mitochondrial cyto-C mediated apoptotic pathway is corrected. Side by side ROS mediated extrinsic pathway of germ cell apoptosis is also corrected by this phytomolecule. The said fraction has two phytomolecules focused by TLC. The nature of the concerned phytomolecules is beyond our knowledge at present and work is going on to explore it.

\section{CONCLUSION}

From the results of this experiment it may be concluded that $28 \mathrm{~d}$ duration is the threshold duration for the management of diabetesinduced testicular hypofunction by the ethyl acetate fraction of methanolic extract of $C$. sinensis at a threshold dose of $100 \mathrm{mg} / \mathrm{kg}$ body weight twice per day. Isolation of active constituent is under process and hopefully would be unfolded from the near future work.

\section{ACKNOWLEDGMENT}

The financial support from 'National Tea Research Foundation (NTRF), Govt. of India' [Scheme Code: 172/2014] to conduct this work is gratefully acknowledged.

\section{AUTHORS CONTRIBUTIONS}

Barnali Das performed the research work and wrote the total manuscript. Baisakhi Biswas helped to perform the research work. Prof. Debidas Ghosh designed the experiment, supervised the entire experiment, analysed the results critically and edited the manuscript.

\section{CONFLICT OF INTERESTS}

The authors have declared that there is no conflict of interest

\section{REFERENCES}

1. Sharma N, Kar A. Combined effects Gymnema sylvestre and glibenclamide on alloxan-induced diabetic mice. Int J Appl Pharm 2014;6:11-4.

2. Jain R, Jain P, Jain P. A review on treatment and prevention of diabetes mellitus. Int J Curr Pharm Res 2016;8:16-8.

3. Temidayo SO, Stefan SD. Diabetes mellitus and male infertility. Asian Pac J Reprod 2018;7:6-14.

4. Sanguinetti RE, Ogawa K, Kurohmaru M, Hayashi Y. Ultrastructural changes in mouse leydig cells after streptozotocin administration. Exp Anim 1995;44:71-3.

5. Martins AD, Majzoub A, Agawal A. Metabolic syndrome and male infertility. World J Mens Health 2018;36:e37.

6. Pourmasumi S, Sabeti P, Rahiminia T, Mangoli E, Tabibnejad N, Talebi AR. The etiologies of DNA abnormalities in male infertility: an assessment and review. Int J Reprod Biomed (Yazd) 2017;15:331-44.

7. Dhaliwall C, Erinmacpherson, Richardson J. Effectiveness of telephone-delivered interventions for increasing physical activity levels in persons with type 2 diabetes or hypertension: a systematic review. J Critical Rev 2015;2:6-11.

8. Chang CLT, Chen YC, Chen HM, Yang NS, Yang WC. Natural cures for type 1 diabetes: a review of phytochemicals, biological actions, and clinical potential. Curr Med Chem 2013;20:899-907.

9. Kan J, Velliquette RA, Grann K, Burns CR, Scholten J, Tian F, et al. A novel botanical formula prevents diabetes by improving insulin resistance. BMC Complementary Altern Med 2017;17:352.

10. Tiwari P, Tamrakar AK, Ahmad R, Srivastava MN, Kumar R, Lakshmi V, et al. Antihyperglycaemic activity of Ceriops tagal in normoglycaemic and streptozotocin-induced diabetic rats. Med Chem Res 2008;17:74-84.

11. Chacko SM, Thambi PT, Kuttan R, Nishigaki I. Beneficial effects of green tea: a literature review. Chin Med 2010;5:13.

12. Wolfram S. Effects of green tea and EGCG on cardiovascular and metabolic health. J Am Coll Nutr 2007;26:373-88.

13. Biswas B, Das B, Jana K, Ghosh D. Evaluation of antidiabetic and antioxidative efficacy of ethyl acetate fraction of methanolic extract of Camellia sinensis (green tea) leaves in streptozotocin induced diabetic albino rat. Int J Phytomed 2017;9:305-14.

14. Chatterjee K, Ali KM, De D, Bera TK, Jana K, Maiti S, et al. Hyperglycemia-induced alteration in reproductive profile and its amelioration by the polyherbal formulation MTEC (modified) in streptozotocininduced diabetic albino rats. Biomarkers Genomic Med 2013;5:54-66.

15. Vasundhara CCS, Gayatri DS. Antihyperlipidemic property of Boerhavia diffusa leaf extract in streptozotocin-induced diabetic rats. Asian J Pharm Clin Res 2018;11:173-6.

16. Thilagam E, Chidambaram K, Mandal SC. Antidiabetic activity of Senna surattensis in alloxan-induced diabetic rats. Asian J Pharm Clin Res 2018;11:160-3.

17. Panda DK, Ghosh D, Bhat B, Talwar SK, Jaggi M, Mukherjee R. Diabetic therapeutic effects of ethyl acetate fraction from the roots of Musa paradisiaca and seeds of Eugenia jambolana in streptozotocin-induced male diabetic rats. Methods Find Exp Clin Pharmacol 2009;31:571-84. 
18. Ali KM, Bera TK, Mandal S, Barik BR, Ghosh D. Attenuation of diabetic disorders in experimentally induced diabetic rat by methanol extract of seed of Holarrhena antidysenterica. Int J Pharmtech Res 2009;1:1205-11.

19. Chandalia HB, Sadikot S, Bhargav DK, Krishnaswamy PR. Estimation of glycosylated hemoglobins by a simple chemical method and its use in monitoring control of diabetes mellitus. J Assoc Physicians India 1980;28:285-6.

20. Ohakawa H, Oshishi N, Yagi K. Assay for lipid peroxidation in animal tissue by the thiobarbituric acid reaction. Anal Biochem 1979;75:351-8.

21. Slater TF. Overview of methods used for detecting lipid peroxidation. Methods Enzymol 1984;105:283-93.

22. Matyus L, Szabo GJr, Resli I, Gaspar R Jr, Damjanovich S. Flow cytometric analysis of viability of bull sperm cells. Acta Biochim Biophys Acad Sci Hung 1984;19:209-14.

23. Garner DL, Thomas CA, Joerg HW, Dejarnette JM, Marshall CE. Fluorometric assessments of mitochondrial function and viability in cryopreserved bovine spermatozoa. Biol Reprod 1997;57:1401-6.

24. Srivastava TG. Orientation training course on research methodology in reproductive medicine. Department of Reproductive Medicine, National Institute of Health and Family Welfare, New Delhi; 2001. p. 55-8.

25. Ghosh A, Jana K, Pakhira BP, Ghosh D. Antiapoptotic efficacy of seed of Eugenia jambolana on testicular germ cell in the experimental diabetic rat: a genomic study. Androl 2015;48:282-92.

26. Henry RJ, Chiamori M, Golub OJ, Berkman S. Revised spectrophotometric methods for the determination of glutamate oxaloacetic transaminase, glutamate pyruvate transaminase and lactic acid dehydrogenase. Am J Clin Pathol 1960;34:381-98.

27. Sokal RR, Rohle FJ. Introduction to analysis of variance. In: Sokal RR, Rohle FJ. editors. Biometry. New York: WH Freeman and Company; 1997. p. 179-206.

28. Hassan IA, Nasiru IA, Malut AM, Abdulkadir SI, Ali AS Phytochemical studies and thin layer chromatography of leaves and flower extracts of Senna siamea lam for possible biomedical applications. J Pharmacogn Phytother 2015;7:18-26.
29. Alves MG, Oliveira PF. Diabetes mellitus and male reproductive function: where we stand. Int J Diabetol Vasc Dis Res 2013;1:101-3.

30. Maresch CC, Stute DC, Alves MG, Oliveira PF, Kretser DM, Linn T. Diabetes-induced hyperglycemia impairs male reproductive function: a systematic review. Hum Reprod Update 2018;24:86-105.

31. Mallick C, Bera TK, Ali KM, Chatterjee K, Ghosh D. Diabetesinduced testicular disorders vis-à-vis germ cell apoptosis in albino rat: remedial effect of hexane fraction of root of Musa paradisiaca and leaf of Coccinia indica. J Health Sci 2010;56:641-54.

32. Marchetti C, Obert G, Deffosez A, Formstecher P, Marchetti P. Study of mitochondrial membrane potential, reactive oxygen species, DNA fragmentation and cell viability by flow cytometry in human sperm. Hum Reprod 2002;17:1257-65.

33. Brown SG, Publicover SJ, Mansell SA, Lishko PV, Williams HL, Ramalingam $\mathrm{M}$, et al. Depolarization of sperm membrane potential is a common feature of men with subfertility and is associated with low fertilization rate at IVF.Hum Reprod 2016;31:1147-57.

34. Ghosh A, Jana K, Ali KM, De D, Chatterjee K, Ghosh D. Corrective role of Eugenia jambolana on testicular impairment in streptozotocin-induced diabetic male albino rat: An approach through genomic and proteomic study. Androl 2014;46:296-307.

35. Chaki SP, Ghosh D, Misro MM. Simultaneous increase in germ cell apoptosis and oxidative stress under acute unilateral testicular ischaemia in rat. Int J Androl 2003;26:319-28.

36. Stabler T, Kenjale A, Ham K, Jelesoff N, Allen J. Potential mechanisms for reduced delivery of nitric oxide to peripheral tissues in diabetes mellitus. Ann N Y Acad Sci 2010;1203:101-6.

37. González F, Sia CL, Shepard MK, Rote NS, Minium J. Hyperglycemia-induced oxidative stress is independent of excess abdominal adiposity in normal-weight women with polycystic ovary syndrome. Hum Reprod 2012;27:3560-8.

38. Maheshwari A, Misro MM, Aggarwal A, Sharma RK, Nandan D. Pathways involved in testicular germ cell apoptosis induced by $\mathrm{H}_{2} \mathrm{O}_{2}$ in vitro. FEBS J 2009;276:870-81. 